\title{
Rosette-like Structure: A Main Dermoscopic Feature in a Small Trichilemmal Cyst
}

\author{
Giulia Bazzacco ${ }^{1}$, Enrico Zelin ${ }^{1}$, Carlo Alberto Maronese ${ }^{2}$, Vittorio Ramella ${ }^{3}$, \\ Diego Signoretto $^{4}$, Iris Zalaudek ${ }^{1}$, Nicola Di Meo ${ }^{1}$
}

\author{
1 Dermatology Clinic, Maggiore Hospital, University of Trieste, Trieste, Italy \\ 2 Dermatology Unit, Fondazione IRCCS Cà Granda Ospedale Maggiore Policlinico, Milan, Italy \\ 3 Plastic Surgery Department, Cattinara Hospital, ASUGI, Trieste, Italy \\ 4 Pathological Anatomy and Histology Department, Cattinara Hospital, University of Trieste, Trieste, Italy.
}

Key words: trichilemmal cyst, rosette, dermoscopy

Citation: Bazzacco G, Zelin E, Maronese CA, et al. Rosette-like structure: a main dermoscopic feature in a small trichilemmal cyst. Dermatol Pract Concept. 2022;12(1):e2022021. DOI: https://doi.org/10.5826/dpc.1201a21

Accepted: May 26, 2021; Published: January 2022

Copyright: $@ 2022$ Bazzacco et al. This is an open-access article distributed under the terms of the Creative Commons AttributionNonCommercial License (BY-NC-4.0), https://creativecommons.org/licenses/by-nc/4.0/, which permits unrestricted noncommercial use, distribution, and reproduction in any medium, provided the original authors and source are credited.

Funding: None.

Competing interests: None.

Authorship: All authors have contributed significantly to this publication and approved the final version of the submitted paper. NDM and IZ defined the design and intellectual content of the paper. GB searched for literature, wrote the draft, edited the manuscript and the tables, preparing them for submission. EZ, CAM, and VR reviewed the article with consistent integrations. DS analyzed the histology samples and contributed to image collection.

Corresponding author: Enrico Zelin, MD, Dermatology Clinic, Hospital Maggiore, Trieste, Italy. E-mail address: enrico.zelin@gmail.com

\section{Introduction}

Trichilemmal cysts (TCs), also called pilar cysts, represent the second most common type of cutaneous cysts, after epidermal ones [1]. TCs most commonly occur in middle-aged women and have a predilection for the scalp but can occasionally show different locations. They appear as solitary or multiple intradermal palpable papules/nodules, occurring as sporadic lesions or in hereditary/familial settings with autosomal dominant transmission [1]. From a histological point of view, TCs have an undulating epithelial wall with no granular layer and a compact keratinization and reveal an isthmic origin [1].

\section{Case Presentation}

A 36-year-old woman was referred to our clinic with an asymptomatic papule of $1 \mathrm{~mm}$ in diameter above her right eyebrow that relapsed after treatment with cryotherapy, in absence of other skin lesions (Figure 1A). On dermoscopy, shiny white areas arranged as a four-leaf clover (rosette-like structure) with a minimal erythematous background was seen (Figure 1B). The lesion was excised, and histopathological examination indicated a multilayer cystic neoformation with eosinophilic cells positive for high molecular weight cytokeratin $(\mathrm{CK} 34 \mathrm{Be} 12+)$ and absence of the granular layer, consistent with the diagnosis of TC (Figure 2, A-C).

On clinical examination, TCs appear as smooth, mobile, firm, dermal or subcutaneous papules or nodules with a typical diameter of 10-20 mm. They do not characteristically present visible pores [1]. Dermoscopy usually shows a pinkish-yellow or homogeneous yellowish-white area with a peripheral erythematous halo and sometimes, due to the Tyndall effect, the keratin material appears blueish [1]. In the present case, the TC was very small (1 mm papule) and 
showed a white shiny rosette-like structure on dermoscopic evaluation. In the literature, the precise morphological correlate of rosettes is not known, since they are not specific and can be seen in various cutaneous lesions, mainly in actinic keratoses, basal cell carcinomas and squamous cell carcinomas, and rarely in cysts. This rosette-like pattern can be probably caused by horny material in the adnexal opening or by concentric perifollicular fibrosis [2].

\section{Conclusions}

Differential diagnosis of TCs can include various entities, such as other cystic lesions but also basal cell carcinoma, squamous cell carcinoma, sebaceous hyperplasia and syringoma (Table 1) [2]. Moreover, these cysts can be subject to inflammation, infection, and enlargement, but rarely grow more extensively, forming proliferating TCs (adnexal tumors

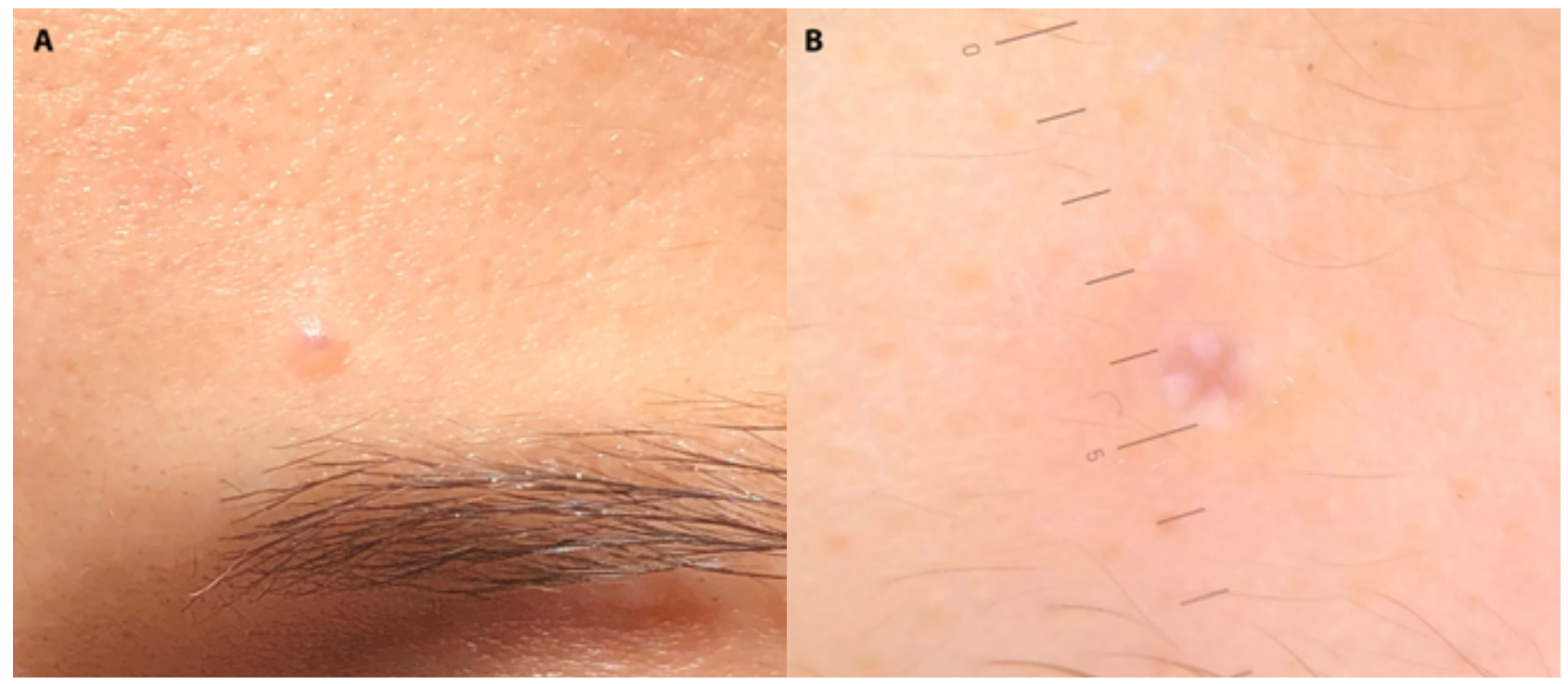

Figure 1. Clinical and dermoscopic appearance of the trichilemmal cyst. (A) A small 1-mm papule above the eyebrow of the patient. (B) Dermoscopy shows shiny white areas arranged as a four-leaf clover (rosette-like structure) with a minimal erythematous background.

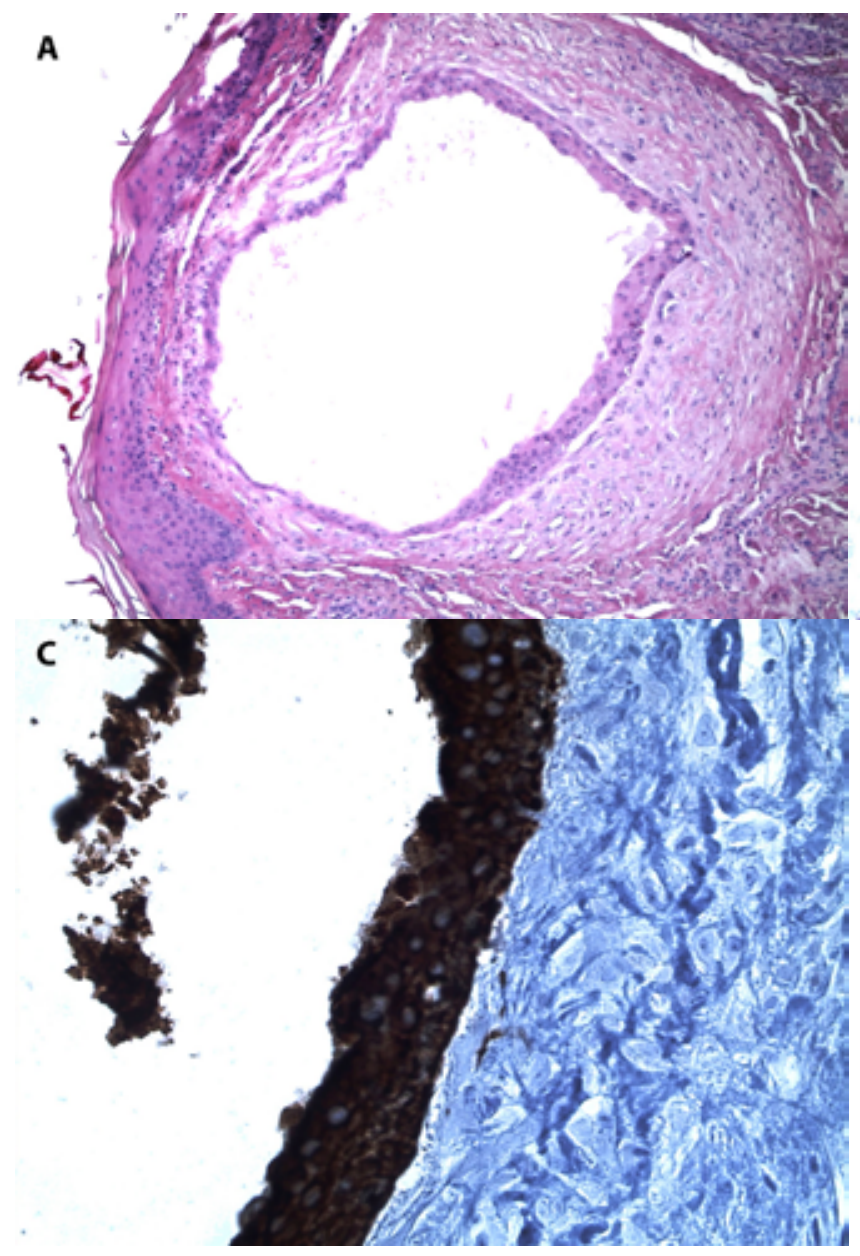

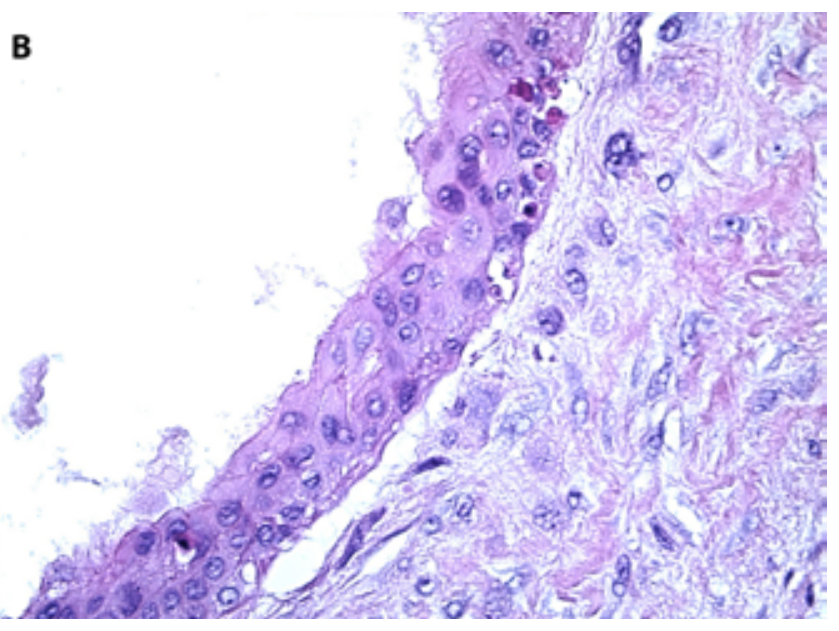


Table 1. Dermoscopic Clues That Differentiate Trichilemmal Cyst from its Main Differential Diagnoses

\begin{tabular}{|c|c|}
\hline Lesion & Classic Dermoscopic Criteria \\
\hline Trichilemmal cyst & $\begin{array}{l}\text { Pinkish-yellow or homogeneous yellowish-white background } \\
\text { Peripheral erythematous halo } \\
\text { Absence of pore sign } \\
\text { Blue pigmentation (Tyndall effect of keratin) }\end{array}$ \\
\hline Epidermal cyst & $\begin{array}{l}\text { Yellowish-white papule } \\
\text { Pore sign: keratin-filled, circular orifice, whitish, yellow, brown } \\
\text { or black in color } \\
\text { Wobble sign (movement of the lesion with respect to the } \\
\text { surrounding tissues, except for the pore, which represents the } \\
\text { site of anchorage of the cyst) }\end{array}$ \\
\hline Basal cell carcinoma & $\begin{array}{l}\text { Arborizing vessels, sort fine telangiectasias Ulceration, erosions } \\
\text { Maple-leaf like, spoke-wheel and concentric structures } \\
\text { Blue-gray globules, blue-ovoid nests }\end{array}$ \\
\hline Squamous cell carcinoma & $\begin{array}{l}\text { Presence of keratin, especially in conjunction with blood spots } \\
\text { Coiled vessels } \\
\text { White structureless zones, white circles (highly differentiated } \\
\text { SCCs) } \\
\text { Predominantly red color, bleeding and ulcerations (poorly } \\
\text { differentiated SCCs) }\end{array}$ \\
\hline Syringoma & $\begin{array}{l}\text { Yellowish-brownish structures } \\
\text { Structureless background } \\
\text { Reticular vessels }\end{array}$ \\
\hline Sebaceous hyperplasia & $\begin{array}{l}\text { Central umbilication surrounded by aggregated polylobular } \\
\text { white-yellowish structures (cumulus sign); this global } \\
\text { appearance is known as bonbon toffee sign } \\
\text { Surrounding crown of vessels at } \\
\text { the periphery }\end{array}$ \\
\hline
\end{tabular}

SCC $=$ squamous cell carcinoma.

usually with a benign behavior) or may even undergo malignant transformation. Therefore, when there is suspicion of TC, it is appropriate to proceed to radical surgical excision with histological examination in order to exclude malignant tumors and prevent complications.

In conclusion, dermoscopy represents a noninvasive tool that allows the identification of specific morphological features in different skin tumors. It significantly improves the early diagnosis of cutaneous lesions and helps in choosing the best treatment options for each case based on the suspected diagnosis. In this article, we described a very characteristic dermoscopic pattern associated with a small TC. The prompt surgical treatment and subsequent histopathological examination aided in a diagnosis of certainty and in prevented the growth of this lesion that was localized to an aesthetic area.
Informed consent: Written informed consent for publication of her clinical details and clinical images was obtained from the patient.

\section{References}

1. Gencoglan G, Karaarslan IK, Akalin T, Ozdemir F. Trichilemmal cyst with homogeneous blue pigmentation on dermoscopy. Australas J Dermatol. 2009;50(4):301-302. DOI: 10.1111/j.14400960.2009.00566.x. PMID: 19916979.

2. Haspeslagh M, Noë M, De Wispelaere I, et al. Rosettes and other white shiny structures in polarized dermoscopy: histological correlate and optical explanation. J Eur Acad Dermatology Venereol. 2016;30(2):311-313. DOI: 10.1111/jdv.13080. PMID: 25786770 . 